\title{
ВАРИАТИВНОСТЬ ИСПОЛЬЗОВАНИЯ СЕРИЙНОЙ АВТОМОБИЛЬНОЙ ПРОДУКЦИИ ДЛЯ ВЫПОЛНЕНИЯ СПЕЦИАЛЬНЫХ ГРУЗОПОДЬЕМНЫХ ЗАДАЧ
}

\section{VARIABILITY IN THE USE OF MASS-PRODUCED AUTOMOTIVE PRODUCTS FOR SPECIAL LOAD-LIFTING TASKS}

\section{A. Amosov}

E. Mikhailova

Summary. The solution of the problem of increasing the productivity of auto-evacuators and cranes on the chassis of serial cars largely depends on solving the issues of mastering the production of new types of heavyduty vehicles, developing and creating advanced technological processes for maintenance and operation.

Compared with a simple truck, vehicles equipped with a manipulator have a number of advantages: higher technical and economic indicators; the ability to vary the load capacity within a wider range; service by one driver of several transport units, and others.

The efficiency of using such units is mainly determined by the combination of their operational properties, which require rational management at the design, production and operation stages.

Keywords: unit, special transport, design, layout, creation, load capacity, loading, auto-evacuators, transportation, telescopic boom, crawler.
Амосов Алексей Германович

Ассистент, Московский авиационный институт (национальный исследовательский университет) lamosov@yandex.ru

Михайлова Екатерина Вячеславна Ассистент, Московский авиационный институт (национальный исследовательский университет) evmihailova@inbox.ru

Аннотация. Решение задачи повышения производительности автоэвакуаторов и кранов на шасси серийных автомобилей во многом зависит от решения вопросов освоения производства их новых типов большой грузоподъемности, разработки и создания прогрессивных технологических процессов обслуживания и эксплуатации.

По сравнению с простым грузовым автомобилем автомобили оснащенные манипулятором имеют ряд преимуществ: более высокие технико-экономические показатели; возможность варьирования грузоподъемности в более широких пределах; обслуживание одним водителем нескольких транспортных единиц и другие.

Эффективность использования таких агрегатов главным образом определяется совокупностью их эксплуатационных свойств, которые требуют рационального управления на стадиях проектирования, производства и эксплуатации.

Ключевые слова: агрегат, специальный транспорт, проектирование, компоновка, создание, грузоподъемность, загрузка, автоэвакуаторы, транспортировка, телескопическая стрела, гусеничный ход.

подвеску, но могут применяться различные клещевые или специализированные захваты или даже электромагниты. На агрегатах грузоподъемностью до 10т включительно, телескопические стрелы двухсекционные, а на кранах грузоподъемностью свыше 10т - трех- и более секционные.

Целью данной работы является создание и параметризация инвариантной конструкции телескопической стрелы таким образом, чтобы при изменении ее параметров можно было получить стрелу любого вида (рис. 1).

\section{Мето ология}

Анализ конструкций современных телескопических стрел позволяет формально описать любую из них 


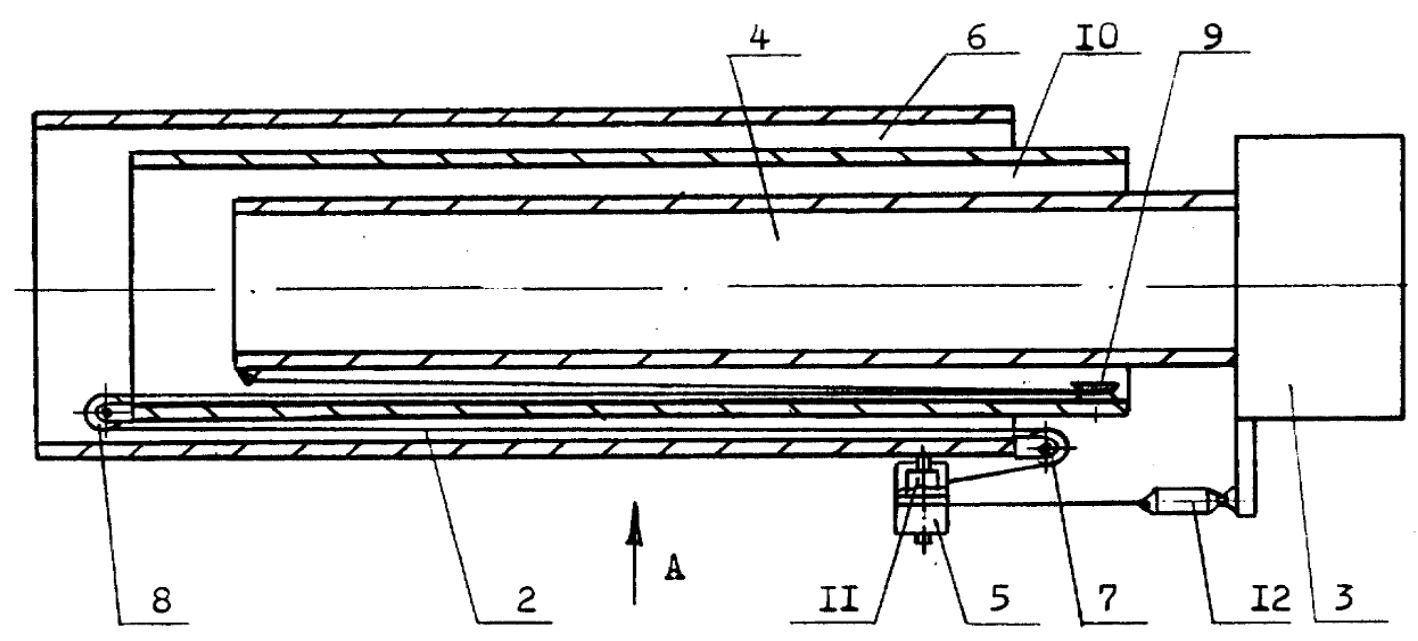

Рис. 1. Схематическое устройство механизма выдвижения секций телескопической стрелы

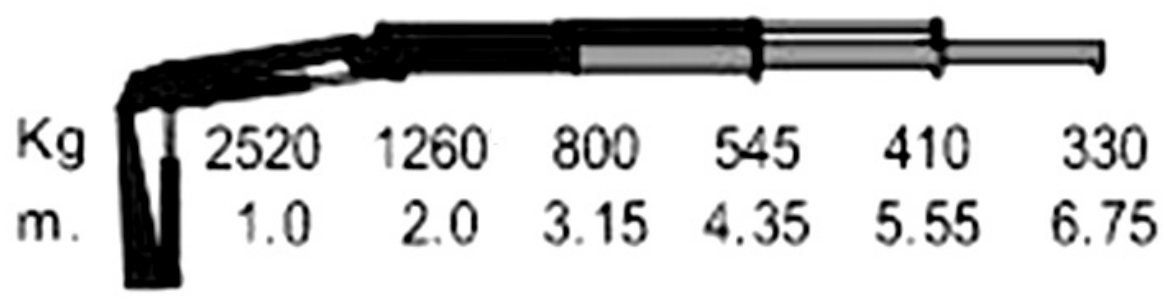

Рис. 2. Соотношение грузоподъемности и вылета стрелы для крана - манипулятора AmcoVeba $1033 \mathrm{~S}$

в виде массива данных, варьируя которым можно получить стрелу любого класса:

$$
\| \text { A B C HS P Q R M } \| \text {, }
$$

где А — минимальный вылет;

B - максимальный вылет;

C - соотношение вылет / грузоподъемность;

H - максимальная высота подъема стрелы;

$\mathrm{S}$ - максимальный грузовой момент;

P - скорость поднимания/опускания груза;

$\mathrm{Q}$ - номенклатура грузозахватных средств;

$\mathrm{R}$ - количество секций подъемного механизма;

M - масса подъемного механизма.

Некоторые параметры массива могут быть связаны параметрически между собой, например, максимальный вылет стрелы равен сумме длин всех секций (рис. 2).

На сегодняшний день существует два способа исполнения грузовой платформы загрузочных агрегатов:

- грузовая платформа совмещена с подъемным механизмом;

- грузовая платформа выполнена отдельно от подъемного механизма.
Если грузовая платформа не предусмотрена конструкцией, то такой объект, строго говоря, не является загрузочным агрегатом (чаще всего такие машины относятся к категории автомобильных кранов), и в данной работе они не будут рассматриваться.

Другой тип грузовой платформы, которая выполнена отдельно от подъемного механизма, предназначен для перевозки различных габаритных и негабаритных грузов, чаще всего это агрегаты низкий грузоподъемности. В основном они выполняются на шасси серийных грузовых автомобилей категории В или С, при этом платформа располагается позади кабины и обычно выполнена плоской. В ряде случаев она может иметь откидные борта и средства закрепления грузов.

В ряде случаев платформа может быть наклонной и иметь специальные откидные направляющие для заезда автотранспорта (автоэвакуаторы и перевозчики автомобилей) (рис. 3).

Математически плоскую грузовую платформу можно записать в виде следующего массива данных:

$$
\|\mathrm{C} ; \mathrm{D} ; \mathrm{H} ; \mathrm{S} ; \mathrm{V}, \mathrm{m}\|
$$




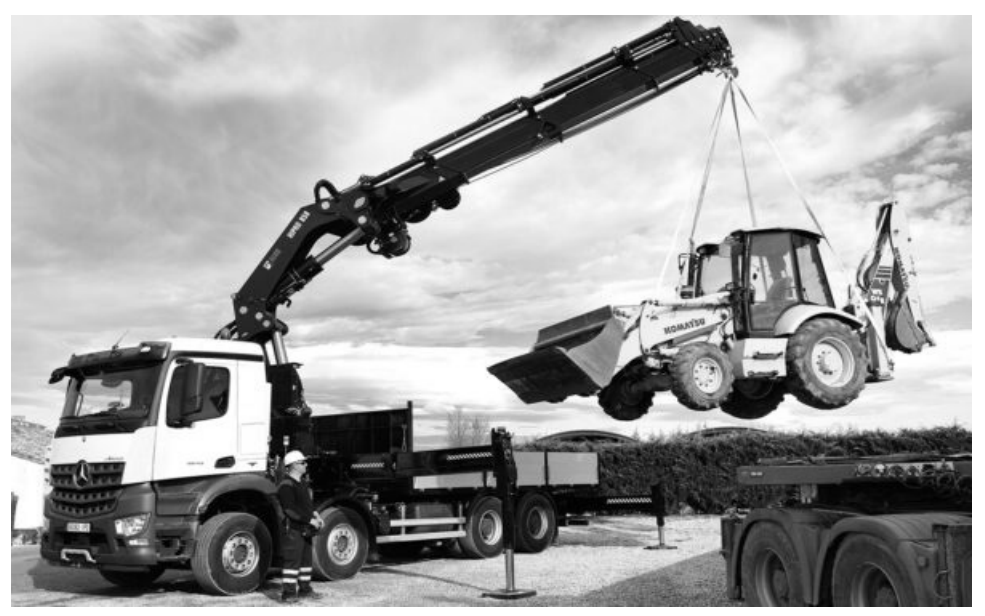

Рис. 3. Работа автоманипулятора
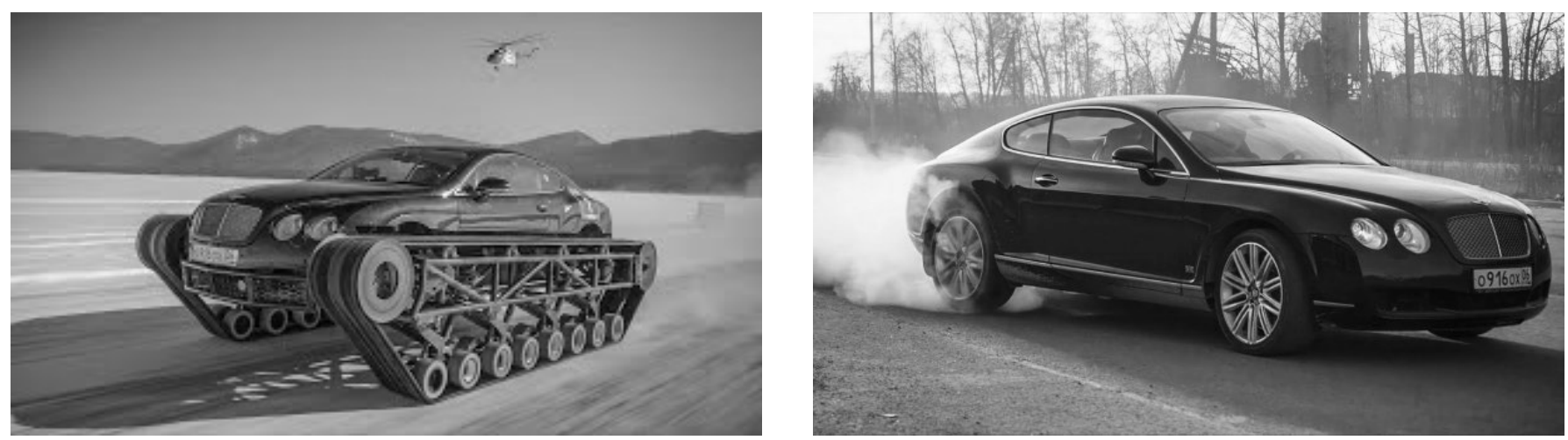

Рис. 4. Пример исполнения автомобиля на гусеничном ходу и колесном.

где C - ширина платформы;

D - длина платформы;

H- высота платформы;

S - площадь платформы;

$\mathrm{V}$ - максимальный объем, занимаемый грузом.

m - максимальная масса груза.

В настоящий момент существует множество вариантов исполнения грузовой платформы, но при проектировании наблюдается тенденция в ограничении их типов, с целью унификации. Основные различия касаются геометрических размеров платформы и максимальной массы перевозимого груза, в зависимости от класса применяемого шасси.

На сегодняшний день для наземного транспорта существует два типа шасси - на колесном и гусеничном ходу, причем наибольшее распространение получили колесные машины. Это в первую очередь объясняется желанием разработчиков создавать как можно более универсальные машины, как в плане грузоподъемности, так и проходимости. Считается, что гусеничные машины имеют более высокую проходимость и меньшее давление на грунт, однако, за счет увеличения осей в колесных машинах и ширины профиля самих колес можно добиться практически таких же показателей проходимости, как у гусеничных машин, а в ряде случаев даже превзойти их [1]. При этом гусеничные машины имеют ограничения по движению по дорогам общего пользования, а колесные - нет. (рис. 4)

Поэтому в данной работе будут рассмотрены только колесные агрегаты широкой номенклатуры.

Для агрегатов низкой грузоподъемности (до 3 тонн) вполне годятся двухосные шасси обычной или повышенной проходимости на базе серийно выпускающихся грузовых автомобилей категории В или С. К ним относятся, в частности, машины Российского производства «Газель Некст» (ГАЗ-3302) с удлиненной платформой, и установленным краном - манипулятором малой грузоподъемности. 
Агрегаты средней грузоподъемности, как правило, создаются на базе грузовых автомобилей категории C, и имеют грузовые платформы большей размерности.

Агрегаты высокой грузоподъемности с грузовой платформой второго типа практически не встречаются, поскольку при таких габаритах и массе груза совместное использование подъемного механизма и грузовой платформы уже нецелесообразно. Что касается платформ первого типа, совмещенных с погрузочным оборудованием, то они были описаны

Математически тип шасси можно записать в виде массива данных:

$$
\|\mathrm{A} ; \mathrm{B} ; \mathrm{m} ; \mathrm{S} ; \mathrm{P}\|,
$$

где A - тип шасси (автомобиль, полуприцеп и т.д.);

В - категория транспортного средства;

$\mathrm{m}$ - максимальная масса перевозимого груза и оборудования;

S - габаритные размеры (площадь) места под грузовую платформу и оборудование;

P - мощность силовой установки.

К служебному и дополнительному оборудованию, рассматриваемому в в данной работе относятся:

- вспомогательные силовые установки, электрогенераторы, масляные насосы и т.д., предназначенные для обеспечения работы транспортно - загрузочного оборудования;

- средства закрепления и фиксации перевозимого груза;

- средства закрепления и фиксации погрузочного оборудования в транспортном положении;

- запасные части, расходные материалы, инструмент;

- бытовое оборудование и принадлежности.

В процессе компоновки служебного оборудования проектировщик старается максимально унифицировать его, уменьшить количество используемых типоразмеров. При различных компоновочных схемах транспортно - загрузочных агрегатов это приведёт к снижению временных и материальных затрат на перекомпоновку.

После определения основных типоразмеров служебного и вспомогательного оборудования проектировщик заказывает их у специализирующихся на их изготовлении фирмах либо разрабатывает сам.

\section{Обсужкения}

Таким образом, при проектировании машин такого типа почти всегда ставится задача создания высоко-про- ходимого и маневренного транспортно - погрузочного средства относительно небольшой грузоподъемности, способного решать самый различный круг задач. К сожалению, машины такого типа практически не выпускаются, а попытки приспособить существующую технику (грузовые автомобили небольшой грузоподъемности) для эксплуатации в таких условиях не позволяют решать поставленных задач в полной мере.

При этом многообразие схем и вариантов компоновочных решений не позволяет исследовать всю область реализуемых вариантов построения транспортно - загрузочных агрегатов без привлечения современных компьютерных технологий. В известных на сегодняшний день публикациях и исследованиях вопросы автоматизированного проектирования обычно рассматриваются на уровне концепций построения отдельных и сильно обобщенных компоновочных схем, или в них описываются только лишь конечные результаты применения программных продуктов для решения отдельных частных задач (например, телескопической стрелы, колесного хода, систем поворота стрелы, силовой установки и т.д.). Стоит также отметить, что большинство распространенных систем автоматизированного проектирования ориентированы на решение указанного класса задач с помощью использования существенно ограниченного набора средств современных интегрированных CAD/CAM/CAE систем.

При этом работами в области автоматизированного проектирования транспортно - загрузочных агрегатов занимались как в нашей стране, так и за рубежом, о чем имеется достаточно много публикаций разного уровня.

Проектирование таких объектов обычно начинается с изучения технических характеристик и конструкций уже имеющихся в эксплуатации образцов. Эта информация часто оказывается неполной и ее приходится собирать в различных источниках (журналы, презентации, каталоги производителей и т.д.).

Так, в статье [2] рассматривается работа фронтальных погрузчиков в различных условиях эксплуатации. При проектировании таких машин важно определить конечные геометрические размеры. Они должны быть связаны со всеми определяющими параметрами. В качестве главного определяющего параметра рассматривается грузоподъемность. Зависимости других определяющих параметров формируются с помощью теории подобия. Оптимизация конструкции проектируемого изделия достигается за счет анализа этих зависимостей и использования полученных результатов на стадии технического предложения и эскизного проекта.

В монографии [3] рассмотрены возможности и ограничения повышения эффективности универсальных малогабаритных погрузчиков с бортовым поворотом пу- 
тем совершенствования конструктивной схемы и оптимизации параметров подсистем привода. Представлен новый метод обоснования определяющих параметров, принимаемых к оптимизации, базирующийся на априорной и апостериорной информации. Даны критерии оценки эффективности и комплексной оптимизации параметров машин на ранних стадиях проектирования. На основе физико-математического моделирования и статистического анализа значений конструктивных и эксплуатационных параметров машин показаны перспективы дальнейшего развития конструкций и технологических схем работы данного класса машин со сменными рабочими органами. Приведена методика и результаты экспериментальных исследований параметров динамического нагружения машины.

В статье [4] приведен анализ конструктивных схем фронтального погрузчика с точки зрения их статической устойчивости. Выявлено влияние ориентации и места положения горизонтального шарнира (балансира) на значение критической опрокидывающей нагрузки, на распределение нормальных реакций между колесами и характер опрокидывания. Предложена математическая модель оценки конструктивной схемы машины с шарнирно-сочлененной рамой.

Имеются и другие публикации по данной тематике.

\section{Выво $\Delta$}

Представленное рассмотрение показывает, что использование таких машин и агрегатов является широкой областью, в изучении которой необходимо приложение многих разделов современного естествознания и техники. Не вызывает сомнений, что будет продолжаться как рост исследований в этой области, так и увеличение объемов практических применений объектов такого типа.

При этом анализ приведенных работ свидетельствует о достаточно ограниченном числе работ в области исследования и проектирования транспортных машин всего спектра грузоподъемности. При этом и имеющиеся исследования не лишены определенных недоработок, несмотря на большое количество публикаций по частным вопросам и попыткам построения обобщенных методов автоматизированного проектирования таких объектов.

Заканчивая обзор некоторых достижений в создании объектов такого типа, следует отметить, прежде всего, актуальность и необходимость проведения дальнейших изысканий в данном направлении, о чем свидетельствует значительный интерес, проявляемый исследователями к этому вопросу.

\section{ЛИТЕРАТУРА}

1. Макаров В.С. 0 проходимости лесозаготовительных машин на гусеничном ходу и агрегатных машин на их базе // Клубничкин В. Е., Клубничкин Е. Е., Зезюлин Д. В., Беляков В. В. // Труды НГТУ им. Р. Е. Алексеева.— 2016. — № 4 (115).— С. 169-175

2. Щемелев А. М. Определение производительности одноковшовых фронтальных погрузчиков // Науменко А. Е., Бужинский А. Д., Шибеко А. С. //

3. Вестник Белорусско-Российского университета.— 2008. — № 4 (21).-С. 55-61.

4. Минин В.В. Моделирование эксплуатационных параметров малогабаритных погрузчиков // Известия Томского политехнического университета.2010. - Т.— № 2.—C. 20-23.

5. Позин Б.М. Влияние конструктивной схемы фронтального погрузчика на эффективность работы // Трояновская И. П., Вершинский Л. В., Переплётчик 0. А. // Строительные и дорожные машины. - 2008. - № 5. - С. 31-32.

6. Кран-манипуляторы КАМАЗ [Электронный ресурс].— Режим доступа: http://www.fost-motors.ru/brand/kamaz/avtomobili-kamaz-s-km

7. Протасов С. Выбираем манипулятор // «0сновные Средства»._- 2011.—-No 4. [Электронный ресурс]. Режим доступа: http://www.os1.ru/article/pto

8. Великолукский машиностроительный завод. [Электронный ресурс].—Режим доступа: http://www.velmash.com/

9. Janarthanan, B. Longitudinal dynamics of a tracked vehicle:Simulation and experiment/B. Janarthanan, C. Padmanabhan, C. Sujatha// Journal of Terramechanics. 2012. - No 49.-P. 63-72.

10. Wong, J. Y. Development of high-mobility tracked vehicles for over snow operations. Journal of Terramechanics. — 2009. — No 46(4).—P. $141-155$.

11. Макаров, В.С. Снег как полотно пути для транспортных средств / В.С. Макаров, Д. В. Зезюлин, В. В. Беляков // Международный журнал прикладных и фундаментальных исследований. - 2014. - № 4.—C. 21-24

( ) Амосов Алексей Германович ( lamosov@yandex.ru ), Михайлова Екатерина Вячеславна ( evmihailova@inbox.ru ).

Журнал «Современная наука: актуальные проблемы теории и практики» 